\title{
La Libertad de Elección en el Sistema Educativo: El Caso de España
}

\author{
Patricia Villamor \\ Universidad Complutense de Madrid
}

\begin{abstract}
This paper deals with the evolution of educational policy in Spain in relation to school from the arrival of democracy. The objective is to provide a pedagogical analysis of the legal evolution of this concept and its repercussions in daily school practice. One of the most controversial issues in the parliamentary transactions leading to the new laws on education has been the definition of parental rights, in particular the right to choose a school. This right was always interpreted as being restrictive. The work concludes by making the case that diversity of options is the best route to meet the needs of a pluralistic society.
\end{abstract}

Key words: politics of education; school choice; diversity; Spanish education system;

RESUMEN

Este artículo trata la evolución de la política educativa en España en relación con la libertad de elección en educación en los niveles obligatorios de la enseñanza no universitaria partiendo del momento de la llegada de la democracia. El objetivo es realizar un análisis pedagógico de la evolución jurídica de este concepto y sus repercusiones en la práctica diaria. Uno de los temas más controvertidos en la tramitación parlamentaria de las sucesivas leyes educativas ha sido el de la definición de los derechos que competen a los padres, fundamentalmente la configuración del derecho de elección de centro que siempre ha sido interpretado en España de forma muy restrictiva. El trabajo concluye mostrando cómo la diversidad de proyectos educativos es la vía más adecuada para atender a una sociedad pluralista.

Descriptores: política de la educación; libertad de elección; diversidad; sistema educativo español;

RÉSUMÉ

Ce papier traite de l'évolution de la politique éducative en Espagne en relation avec l'école depuis l'arrivée de la démocratie. Le but est de faire une analyse pédagogique de l'évolution légale de ce concept ainsi que de ses répercussions dans la pratique quotidienne scolaire. Une des questions les plus controversées dans les transactions parlementaires conduisant aux nouvelles lois sur l'éducation a été la définition des droits des parents, en particulier le droit de choisir une école, droits qui avaient toujours été interprétés au sens restrictif. L’essai conclut en présentant des arguments en faveur d'une diversité d'options comme étant la meilleure voie pour répondre aux besoins d'une société pluraliste.

Mots-clés: les politiques de l'éducation, le choix d'école, la diversité, le système d'éducation espagnol. 


\section{Introducción}

$\mathrm{E}$ STE ARTÍ́CUlO ANALIZA La EVOlución de la política educativa en España en relación con la libertad de elección en educación en los niveles obligatorios de la enseñanza no universitaria. La normativa suele ayudar a comprender la evolución de los conceptos educativos y el caso que nos ocupa ha sido objeto de polémicas y discusiones jurídicas y pedagógicas. De hecho, uno de los temas más controvertidos en la tramitación parlamentaria de las sucesivas leyes educativas ha sido el de la definición de los derechos que competen a los padres, fundamentalmente la configuración del derecho de elección de centro. La controversia suscitada en torno al reconocimiento de este derecho forma parte de la conflictiva experiencia jurídica y política que la materia educativa ha sufrido en España, que se puso de manifiesto en la gestación del artículo 27 de la Constitución y que no es extraña, aunque con sus peculiaridades, a la vivida en el resto de Europa (Fernández Rodríguez, 2000, p. 15). Dentro del contexto educativo español, la libertad de elección ha tenido un significado y un tratamiento normativo específico que se ha diferenciado claramente de su consideración en la mayoría de los países europeos de nuestro alrededor (exceptuando casi únicamente el caso francés) y del resto de sistemas educativos internacionales ${ }^{1}$. En España, la amplitud de la libertad de elección en educación se ha limitado tradicionalmente y desde la elaboración de la Constitución, a la posibilidad de elegir religión en todos las escuelas (que deben ofertar esta asignatura de manera obligatoria) y a la posibilidad (reconocida legalmente aunque muy difícil en la práctica diaria) de elegir centro escolar, limitada a su vez por la elaboración estatal (concretada más tarde por las propias comunidades autónomas dentro del respeto a la norma del Ministerio de Educación) de los criterios de admisión que deben aplicar todos los centros sostenidos con fondos públicos (tanto los creados por la administración como los de titularidad privada).

El análisis y comentario presentado aquí se centra en las distintas regulaciones legales que afectan a la elección en educación en España, partiendo del momento de la llegada de la democracia. Se ha respetado el orden cronológico para facilitar la comprensión de una normativa legal que ha sido muy confusa en nuestros últimos 30 años de política educativa.

\section{Regulación Jurídica Estatal de la Libertad de Elección: Gobierno de la Unión de Centro Democrático (1977-1982)}

\section{Proyecto de Ley sobre Financiación de la Enseñanza Obligatoria}

En el contexto español es fundamental realizar al menos una referencia al Proyecto de Ley sobre Financiación de la Enseñanza Obligatoria publicado en el Boletín de las Cortes no 160, de 11 de octubre de 1978 (modificado posteriormente en 1979 por la Unión de Centro Democrático). Se elaboró en un período preconstitucional y aunque nunca se llegó a implantar, es el primer proyecto de la etapa democrática que intentaba regular la financiación de un sistema educativo que apoyaba la elección en educación de un modo que no ha vuelto a repetirse. 
En realidad defiende un sistema que posteriormente y con variaciones significativas, incorporará la Ley Orgánica Del Derecho a la Educación elaborada por el Partido Socialista con la denominación de "concierto escolar". Se trataba, sin embargo, de una versión poco trabajada, desarrollada y con pocas especificaciones, que hicieron que el proyecto recibiera los calificativos de "precipitado, impreciso e inmaduro" (Alegre Gómez, 1982, p. 33).

La gratuidad de la enseñanza en los niveles obligatorios se considera un derecho de los alumnos, y se canaliza a través de la percepción por parte de las familias de la misma cantidad que representa el coste del puesto escolar estatal. Esta cantidad recibe el nombre de "ayuda a la gratuidad". Una vez recibida esta suma, los padres o tutores la aplicarán al precio del centro educativo elegido libremente por ellos, cualquiera de titularidad pública o cualquiera de los centros privados adscritos al sistema. Los centros privados elegirían libremente acogerse o no a este sistema.

A pesar de no poder identificarlos plenamente, este sistema de subvenciones es muy similar a la financiación a través de bonos o cheques escolares porque se financia el puesto escolar proporcionando la cantidad económica individualmente a cada familia y no como un todo al centro. En este proyecto, el estado interviene limitando el sistema de mercado al imposibilitar percibir ninguna otra cantidad de las familias.

El 22 de febrero de 1979, los responsables del Programa de Investigaciones Económico Educativas de la Secretaría General Técnica del Ministerio de Educación y Ciencia emitieron un "Informe sobre el cheque escolar", analizando el Proyecto de Ley publicado en el Boletín de las Cortes unos meses antes. Esta vinculación entre el proyecto y la denominación de cheque escolar, no deja lugar a dudas de la inspiración de dicha propuesta. A pesar de ello, en ningún momento podemos encontrar esta terminología, asociada a determinadas teorías políticas y económicas, en el texto normativo pero sí en el informe evaluador, lo que seguramente es un indicativo de la carga ideológica y del carácter, a veces peyorativo, que se ha atribuido a la expresión "cheque escolar" en nuestro país. Las conclusiones del informe apuntaban a que los presupuestos nacionales no podrían sostener un sistema de subvenciones de ese tipo, por lo que la viabilidad financiera del proyecto podía no ser muy realista. Proponían la limitación de los bonos en función, por ejemplo, de las rentas familiares o la distancia a los centros (si los gastos de transporte eran elevados el proyecto no podía lograr su objetivo de reducir las diferencias económicas).

La UCD utilizó la vía de enmienda (Boletín de las Cortes, no 50 de 1 de junio de 1979) sobre el proyecto para introducir modificaciones en su anterior propuesta. La Ley Orgánica del Estatuto de Centros Escolares aprobada por la UCD un año después, anunciaba una ley posterior de financiación de la libertad de elección de centro, basada en su proyecto-enmienda pero no salió adelante. Aunque recoge el mismo espíritu que su predecesor, el proyecto de 1979 introdujo algunas diferencias significativas. Esta vez se trataba de un proyecto de Ley, que se redactó más minuciosamente y que incorporó varias de las enmiendas que había recibido la versión anterior. Uno de los cambios más relevantes fue la obligación de los centros privados subvencionados de regirse por los criterios de admisión aprobados para los centros públicos. Sin embargo, la disposición transitoria primera, permitía a los centros acogidos a las subvenciones recibir de sus 
alumnos o familias cantidades que cubriesen los eventuales desfases entre los costes de dichos centros y los del sector estatal. Este margen de autonomía ha sido eliminado de todas las posteriores regulaciones de las subvenciones a centros privados, en parte porque se intenta asegurar la gratuidad de la enseñanza mediante los módulos económicos aportados a los centros concertados pero limitando considerablemente su autonomía de gestión.

\section{La Constitución Española}

La Constitución Española fue aprobada en referéndum el día 6 de diciembre de 1978 y luego sancionada por el Rey en una sesión conjunta del Congreso de los Diputados y el Senado.

La política educativa que emana desde la Constitución fue uno de los puntos más delicados que se tuvo que superar y donde la redacción fue más ardua. El artículo 27 (eje normativo de la política educativa posterior y de la configuración del sistema educativo) es un pacto abierto a la alternancia política, es decir, es lo suficientemente amplio para que cada partido durante su gobierno, pueda resaltar unos aspectos sobre otros. Pero también es verdad que el consenso entre planteamientos ideológicos diferentes fue muy trabajoso y el compromiso de pacto fue tan apurado que después han surgido dificultades a la hora de hacer factibles algunas de las cuestiones educativas. Las tensiones en torno a los principios de "libertad", como el derecho a la elección de los padres en materia educativa, e "igualdad", como finalidad del sistema educativo, se reprodujeron en la gestación de la Constitución (Fernández Rodríguez, 2000, p. 20). La libertad de elección de centros se discutió, pero finalmente fue omitida en la redacción final del artículo 27. A pesar de ello, determina la concepción de libertad de elección que aplicaremos a partir de entonces en el sistema educativo. En este artículo se reconoce la libertad de enseñanza, y también, de forma simultánea, el derecho a la educación. La situación de este último en el texto no resulta ser técnicamente muy adecuada $^{3}$, aunque encuentra su justificación en la obtención de máxima protección, con la "reserva de ley orgánica" que implicará su desarrollo (el artículo 81.1 introduce la necesidad de desarrollar los derechos fundamentales y las libertades públicas a través de leyes orgánicas, que requieren la mayoría absoluta del congreso para su aprobación), el respeto a su contenido esencial y la garantía que ofrece a su protección el Tribunal Constitucional (artículos 53.2 y 161) (Villar Ezcurra, 1979, p. 156).

Una vez aprobada la Constitución en el Congreso de los Diputados, la Unión de Centro Democrático introdujo en el Senado una modificación (el párrafo 2 del artículo 10) que obligaba a la interpretación de las normas relativas a los derechos y libertades fundamentales (por lo tanto también el artículo 27 sobre la enseñanza), según lo dispuesto en la Declaración Universal de Derechos Humanos y tratados internacionales sobre dicha materia ratificados por España. Esta modificación fue introducida principalmente para garantizar que la libertad de creación de centros docentes se acompaña del derecho a dirigirlos (aclaración no contemplada en el texto constitucional pero recogida por algunos de estos tratados internacionales), junto con la posibilidad de elegir centros diferentes a los establecidos por las autoridades públicas (buscando una 
interpretación más amplia que la recogida en el texto constitucional sobre elección del tipo de educación filosófica y moral). Resulta necesario aclarar que, a través del artículo 10.2 de la Constitución, no se otorga rango constitucional a los derechos y libertades proclamados en los Tratados Internacionales si no están también recogidos en nuestra Constitución.

La Constitución hace varias referencias directa e indirectamente a la educación, y sus artículos son necesarios para interpretar el concepto de libertad de elección así como la limitación de su amplitud. Para facilitar su análisis, los artículos pueden agruparse en tres categorías: los que tratan directamente sobre la enseñanza (a los que he llamado principales), los que articulan las competencias entre el Estado y las Comunidades Autónomas y los que remiten a los textos internacionales de derechos humanos. Sin ánimo de que resulte exhaustivo, creo que es necesario enumerar aquellos artículos que más han determinado el tema que nos ocupa. Por motivos de espacio sólo son reproducidos textualmente aquéllos que son realmente imprescindibles para comprender y analizar la normativa posterior.

1.- Artículos principales.

TÍTULO I: De los Derechos y Deberes Fundamentales.

CAPITTULO II: Derechos y libertades.

Sección 1. ${ }^{\text {- }}$ De los derechos fundamentales y de las libertades públicas.

- Artículo 27.2; artículo 27.4; artículo 27.5; artículo 27.7; artículo 27.8; artículo 27.10.

- Artículo 27.1: Todos tienen el derecho a la educación. Se reconoce la libertad de enseñanza.

- Artículo 27.3: Los poderes públicos garantizan el derecho que asiste a los padres para que sus hijos reciban la formación religiosa y moral que esté de acuerdo con sus propias convicciones.

- Artículo 27.6: Se reconoce a las personas físicas y jurídicas la libertad de creación de centros docentes, dentro del respeto a los principios constitucionales.

- Artículo 27.9: Los poderes públicos ayudarán a los centros docentes que reúnan los requisitos que la ley establezca.

2.- Articulación de competencias entre el Estado y las Comunidades Autónomas.

TÍTULO VIII: De la organización territorial del Estado.

CAPÍTULO III: De las Comunidades Autónomas

- Artículo 148.1 y artículo 148.2.

- Artículo 149.1, artículo 149.2 y artículo 149.3 .

3.- Artículos que remiten a los textos internacionales.

TÍTULO I: De los Derechos y Deberes Fundamentales.

- Artículo 10.2: Las normas relativas a los derechos fundamentales y a las libertades que la Constitución reconoce, se interpretarán de conformidad con la Declaración Universal de Derechos Humanos y los tratados y acuerdos internacionales sobre las mismas materias ratificados por España. 
A continuación, se recogen los artículos más relevantes de los Tratados Internacionales de referencia en relación con la libertad de elección de centro y que deben ser, pues, tenidos en cuenta al interpretar nuestro texto constitucional. Están divididos en cuatro grandes grupos, clasificados por el organismo que los redactó: las Naciones Unidas (ONU), la Organización de las Naciones Unidas para la Educación, la Ciencia y la Cultura (UNESCO), el Consejo de Europa y la Comunidad Europea (CE) y Unión Europea (UE). En este caso sólo se reproducen textualmente los que aportan algo nuevo a la interpretación de la elección en educación.

\section{A. Organización de Naciones Unidas (ONU).}

- Declaración Universal de Derechos Humanos, aprobada por la Asamblea General de las Naciones Unidas el 10 de diciembre de 1948.

- Artículo 26.3: Los padres tendrán derecho preferente a escoger el tipo de educación que habrá de darse a sus hijos.

- Pacto Internacional de Derechos Civiles y Políticos aprobado por la resolución 2200 (XXI) de la Asamblea General de las Naciones Unidas, de 16 de diciembre de 1966. Instrumento de ratificación de 27 de abril de 1977 (BOE no 103, de 30 de abril de 1977).

- Artículo 18.4: Los Estados partes en el presente Pacto se comprometen a respetar la libertad de los padres y, en su caso, de los tutores legales, para garantizar que los hijos reciben la educación religiosa y moral que esté de acuerdo con sus propias convicciones.

- Pacto Internacional de Derechos Económicos, Sociales y Culturales, aprobado por la resolución 2200 A (XXI) de la Asamblea General de las Naciones Unidas, de 16 de diciembre de 1966.

- Artículo 2.1.

- Artículo 13.3: Los Estados partes en el presente Pacto se comprometen a respetar la libertad de los padres y, en su caso, de los tutores legales, de escoger para sus hijos o pupilos escuelas distintas de las creadas por las autoridades públicas, siempre que aquéllas satisfagan las normas mínimas que el estado prescriba o apruebe en materia de enseñanza y de hacer que sus hijos o pupilos reciban la educación religiosa o moral de acuerdo con sus propias convicciones.

- Declaración sobre la Eliminación de todas las formas de Intolerancia y Discriminación fundadas en la Religión o las Convicciones, de 25 de noviembre de 1985.

- Artículo 5.1; artículo 5.2;

- Artículo 6.

- Declaración sobre los derechos de las personas pertenecientes a minorías nacionales o étnicas, religiosas y lingüísticas, aprobada por la Asamblea General en su resolución 47/135 del 18 de diciembre de 1992.

- Artículo 4.4. 


\section{B. Organización de las Naciones Unidas para la Educación, la Ciencia y la Cultura} (UNESCO).

- Convención relativa a la Lucha contra las Discriminaciones en la Esfera de la Enseñanza, adoptada el 14 de diciembre de 1960 por la Conferencia General de la UNESCO, entrando en vigor, de acuerdo con su artículo 14, el 22 de mayo de 1962.

- Artículo 2: En el caso de que el Estado las admita, las situaciones siguientes no serán consideradas como constitutivas de discriminación en el sentido del artículo 1 de la presente Convención:

a) La creación o el mantenimiento de sistemas o establecimientos de enseñanza separados para los alumnos de sexo masculino y para los de sexo femenino, siempre que estos sistemas o establecimientos ofrezcan facilidades equivalentes de acceso a la enseñanza, [...];

b) La creación o el mantenimiento, por motivos de orden religioso o lingüístico, de sistemas o establecimientos separados que proporcionen una enseñanza conforme a los deseos de los padres o tutores legales de los alumnos, [...];

c) La creación o el mantenimiento de establecimientos de enseñanza privados, siempre que la finalidad de esos establecimientos no sea la de lograr la exclusión de cualquier grupo, sino la de añadir nuevas posibilidades de enseñanza a las que proporciona el poder público, [...].

- Artículo 3.

- Artículo 5. 1: Los Estados Partes en la presente Convención convienen:

b) En que debe respetarse la libertad de los padres o, en su caso, de los tutores legales, $1^{\circ}$ de elegir para sus hijos establecimientos de enseñanza que no sean los mantenidos por los poderes públicos, pero que respeten las normas mínimas que puedan fijar o aprobar las autoridades competentes, y 2o de dar a sus hijos, según las modalidades de aplicación que determine la legislación de cada Estado, la educación religiosa y moral conforme a sus propias convicciones; en que, además, no debe obligarse a ningún individuo o grupo a recibir una instrucción religiosa incompatible con sus convicciones;

c) En que debe reconocerse a los miembros de las minorías nacionales el derecho a ejercer actividades docentes que les sean propias, entre ellas la de establecer y mantener escuelas y, según la política de cada Estado en materia de educación, emplear y enseñar su propio idioma, [...].

\section{- Artículo 5.2.}

\section{Consejo de Europa.}

- Primer Protocolo Adicional al Convenio Europeo para la Protección de los Derechos del Hombre y de las Libertades Fundamentales de 20 de marzo de 1952.

- Artículo 2: A nadie se le puede negar el derecho a la instrucción. El estado en el ejercicio de las funciones que asume en el campo de la educación y la enseñanza, respetará el derecho de los padres a asegurar esta educación y esta enseñanza conforme a sus convicciones religiosas y filosóficas. 


\section{Comunidad Europea (CE) y Unión Europea (UE).}

- Resolución del Parlamento Europeo sobre la Libertad de Enseñanza en la Comunidad Europea de 14 de marzo de 1984.

\section{- Párrafo 1.}

- Párrafo 3.

- Párrafo 7: La libertad de educación y de enseñanza incluye el derecho de abrir un centro y de impartir en él una enseñanza; esta libertad incluye el derecho de los padres a elegir para sus hijos, entre centros equivalentes, uno que ofrezca a éstos la enseñanza deseada. A este respecto, el niño debe también poder entrar en un centro que, tanto en la educación como en la enseñanza, no dé la primacía a ninguna religión ni filosofía; [...].

\section{- Párrafo 9.}

- Declaración sobre Derechos y Libertades Fundamentales del Parlamento Europeo de 12 de abril de 1989 .

- Artículo 16: Se asegurará el derecho de los padres a hacer impartir la educación de acuerdo con sus convicciones religiosas y filosóficas.

Estos textos nos ayudan a interpretar el alcance de las prescripciones constitucionales sobre las libertades y derechos educativos. En la Constitución española la única referencia a la elección en educación aparece referida al derecho a elegir la formación religiosa y moral, y ésta aparece dentro del derecho a la educación y no como expresión de la libertad ideológica y religiosa del artículo 16 (Rodríguez Coarasa, 1998), a imagen de lo que ocurre en los textos internacionales. Sin embargo, en el contexto normativo internacional la libertad de enseñanza incluye, entre otros, el derecho a elegir entre diferentes centros docentes, así como la libertad para crear y dirigir los centros creados. No puede hablarse de libertad de enseñanza si no existe una opción para la elección de centro y del tipo de educación que se imparte en el mismo (Villar Ezcurra, 1979, p. 161). Este carácter propio del centro es una posibilidad derivada de la libertad para dirigir centros, que como ya he citado anteriormente, está implícita en la libertad de creación de centros, como se deduce de los anteriores textos legales internacionales.

Posteriormente, el derecho a elegir el tipo de educación ha sido limitado en España a la no interferencia de los poderes públicos en el derecho educativo paterno materno a elegir centros docentes diferentes de los establecidos por las administraciones públicas. Aunque el derecho a la elección de centro no está explícitamente recogido en el artículo 27 de la Constitución, sí lo está en los tratados internacionales. Esta libertad se ve limitada por las necesidades de la planificación y el principal problema que plantea es la necesidad de establecer criterios para la selección de los alumnos en los centros sostenidos con fondos públicos debido a que el número de solicitudes es mayor que el de plazas disponibles.

Quizá los tratados sobre los derechos de las minorías añaden un nuevo matiz a la libertad para elegir el tipo de educación o la educación religiosa y moral conforme a las propias convicciones, ya que se incluyen las oportunidades para aprender la lengua materna, su historia, idioma o cultura. La Convención relativa a la Lucha contra las Discriminaciones en la Esfera de la Enseñanza añade la posibilidad de crear centros 
por motivos lingüísticos o religiosos para satisfacer los deseos de los padres. Además, introduce también la obligación de los Estados de luchar contra las discriminaciones en las admisiones en los centros, reconociendo la problemática que subyace en estos procesos y el compromiso de permitir el acceso a los extranjeros en las mismas condiciones que los residentes. En el Convenio Marco para la protección de las Minorías Nacionales donde se reconoce el derecho de las minorías a crear y dirigir sus propios centros, no se refiere ya únicamente a los aspectos religiosos. El párrafo 3 de la Resolución del Parlamento Europeo sobre la Libertad de Enseñanza de 1984, incluye unos criterios que no pueden condicionar la admisión, entre los que se encuentran la raza, el origen social y la situación económica. El párrafo 7 expone que la libertad de enseñanza incluye la libertad de elección de un centro que imparta las enseñanzas deseadas. Sorprendentemente y contra lo que se ha afirmado en las distintas interpretaciones de nuestro texto constitucional, el párrafo 9 asegura que la libertad de enseñanza implica la obligación del Estado de conceder subvenciones a todos esos centros (de modo similar a lo que ocurre en Holanda). La Constitución Europea en su texto provisional (que por no estar aún vigente jurídicamente no está incluída en los textos anteriores), añade un interesante matiz al hablar de elección de centro conforme a las convicciones pedagógicas, expresión que no habíamos leído en ninguna normativa previa. De hecho, la elección de centro sólo parece limitarse al derecho paterno/ materno de poder elegir una educación acorde a las convicciones morales o filosóficas de la familia. La mayoría de las regulaciones estatales posteriores a la Constitución han favorecido la creación de centros de distintas opciones religiosas y morales para respetar este derecho. Sin embargo, no se interpreta esta normativa desde un punto de vista pedagógico, lo que daría cabida a las distintas opciones educativas dentro del carácter propio o ideario de un centro y a las preferencias familiares sobre ellas. Esta opción pedagógica como parte del ideario está recogida de algún modo en la última ley general educativa (LOE) aprobada en mayo de 2006. Quizá esta interpretación pueda conducir a ampliar el número de verdaderas opciones disponibles en nuestro sistema educativo.

\section{Ley Orgánica por la que se Regula el Estatuto de Centros Escolares (LOECE)}

La Ley Orgánica 5/1980, de 15 de junio, por la que se regula el Estatuto de Centros Escolares (BOE no 154, de 27 de junio de 1980), fue aprobada bajo el gobierno de la Unión de Centro Democrático y se convirtió en la primera ley general de enseñanza del periodo democrático. Era, por tanto, la primera vez que se desarrollaba el artículo 27 de la Constitución.

Su característica primordial es que entendió la libertad de enseñanza como libertad de creación de centros escolares, derivando de ella, el derecho de los titulares de los centros privados a establecer un ideario propio y los derechos de los padres a que sus hijos recibieran una educación acorde con sus convicciones religiosas y morales y a elegir un centro docente de acuerdo con esas convicciones.

El artículo 5 de la LOECE recoge el derecho a la elección del tipo de educación y también, explícitamente, el de elegir centro. En este artículo se asegura, por un lado, que el cumplimiento de este derecho se realiza "dentro del sistema educativo", admitiendo la 
existencia de centros religiosos y, por otro, la posibilidad de financiar cualquier centro de enseñanza obligatoria, sea cual sea su ideario. Además, es también significativo que añade que la elección se basa además de en las convicciones religiosas, en las filosóficas.

Junto a este artículo, el número 35 reconoce como derecho de los alumnos su admisión en un centro escolar de cualquier nivel educativo (con carácter general, sin distinguir entre públicos y privados), "siempre que se cumplan las condiciones establecidas reglamentariamente para el acceso al mismo y existan plazas disponibles. En ningún caso habrá discriminación en el ejercicio de este derecho por razones de lenguas, raza, creencia y situación económico-social”. El segundo párrafo estableció que para los centros financiados con fondos públicos, las convocatorias de plazas vacantes así como los procedimientos concretos de admisión, fueran regulados en otras disposiciones. En cualquier caso, los criterios de admisión debían tener en cuenta la proximidad domiciliaria y la presencia de hermanos en el mismo centro. Ambos criterios han permanecido en todas las regulaciones posteriores hasta la fecha.

Al ser la primera ley educativa que desarrollaba la Constitución Española, la UCD quiso recoger junto a la libertad para crear centros la libertad para dirigirlos (artículos 7 y 32), aunque ésta había sido introducida en el texto constitucional vía referencia a los textos internacionales. Junto a estas dos libertades (creación y dirección), la LOECE reconoció el derecho de los titulares de los centros privados a establecer un ideario educativo propio (artículo 34).

En el documento elaborado por el Partido Socialista Obrero Español (PSOE) y la Federación de Trabajadores de la Enseñanza (FETE) como análisis del proyecto de Ley del estatuto, presentado en 1979, estos dos grupos criticaron fuertemente la regulación del ideario, del que dijeron que fomentaba los "guetos ideológicos o confesionales" (PSOE, 1979, p. 5). La filosofía que subyace en estas críticas (que los socialistas han mantenido desde entonces y han incorporado a sus legislaciones posteriores) se basa en la defensa de que un centro educativo debe reflejar la pluralidad que se encuentra en la sociedad, aunque los centros resulten homogéneos entre sí, frente a la idea mantenida por otros grupos de que un sistema educativo puede reflejar esta sociedad plural, pero cada centro de forma individual debe estar identificado con un proyecto religioso o filosófico propio, que todas las familias compartan. Encontramos en este debate las dos perspectivas educativas posibles en una sociedad diversa como la nuestra; por un lado, la posibilidad de crear centros homogéneos que respeten dentro de ellos la heterogeneidad social, o favorecer la identidad de centros que acojan a una población homogénea y que sea la red de centros en conjunto la que pueda representar la heterogeneidad social.

\section{Sentencia del Tribunal Constitucional 5/1981, de 13 de febrero, relativa a la Ley Orgánica 5/1980 por la que se regula el Estatuto de Centros Escolares}

Una vez aprobada, la LOECE fue objeto de un recurso de inconstitucionalidad, presentado por senadores pertenecientes al Grupo Parlamentario Socialista, Socialistas de Cataluña y Socialistas Vascos, en el que se aducían como inconstitucionales muchos de estos aspectos. El Tribunal Constitucional se pronunció con la sentencia de 13 de 
febrero de 1981 (BOE no 47, de 24 de febrero de 1981).

Esta Sentencia y la siguiente, elaborada en relación con la Ley Orgánica del Derecho a la Educación, son particularmente importantes en la configuración de nuestro sistema educativo. Por un lado, proceden del máximo órgano judicial de nuestro país y por otro, el Tribunal Constitucional no se basó únicamente en la Constitución Española, sino que en ambas sentencias consideró las normas internacionales más importantes. Con estas disposiciones jurídicas el Tribunal llenó de contenido el artículo 27 de la Constitución y estableció cuál sería la interpretación de los instrumentos internacionales en España (Arasanz, 1999, p. 2).

Tomás y Valiente, en su voto particular en la Sentencia, afirma que el derecho a elegir el tipo de educación acorde a sus creencias se refiere más a la educación que a la propia enseñanza, ya que ésta se cierne a la transmisión de conocimientos científicos y aquélla a la comunicación de determinadas convicciones filosóficas, morales o religiosas conformes con una determinada ideología. Justifica esta aseveración añadiendo en el fundamento jurídico quinto de su voto particular que:

"Por ello, nuestra Constitución habla (artículo 27.3) de «formación religiosa y moral»; el artículo 26.3 de la Declaración Universal de 1948 se refiere a la elección del «tipo de educación»; los Pactos internacionales de 1966 de derechos civiles y políticos (artículo 18.4) y de derechos económicos, sociales y culturales (artículo 13.3) hablan de «educación religiosa y/o moral», expresión que aparece también en el artículo 5.1 b) de la Convención para no discriminación en la enseñanza de 1960".

Según su interpretación entonces, no quedaría recogida constitucionalmente la posibilidad de elegir centros por su especialización curricular, ya que esto no refleja las convicciones religiosas. Sin embargo el Tribunal afirma en este sentido que, por un lado, "el derecho a elegir este tipo de formación es distinto del derecho a elegir centro docente que enuncia el artículo 13.3 del Pacto Internacional sobre Derechos Económicos, Sociales y Culturales" (fundamento jurídico octavo) porque elegir un centro significa algo más que elegir una determinada formación religiosa y moral, y por otro, las familias pueden elegir un centro que no haya sido dotado de ideario.

El Magistrado Tomás y Valiente establece también que, para ejercer este derecho los padres pueden elegir una escuela pública, no orientada ideológicamente, o una escuela privada, cada una con su ideología determinada. No se reconoce de hecho en ningún momento de la Sentencia el derecho de los padres a elegir entre los centros públicos, sino que se limita la elección a seleccionar un centro público o un centro privado. En el mismo voto particular considera (fundamento jurídico vigésimo primero) que algunos de los padres que eligen la escuela pública pueden considerar que ejercen su derecho garantizado por el artículo 27.3 de la Constitución de un modo imperfecto o menos satisfactorio que los que eligen un centro con una educación más homogénea ${ }^{3}$. Cuando en una determinada área de escolarización sólo existiesen centros con un mismo ideario y no existieran centros públicos, el Estado debería crearlos, ya que de otro modo se estaría negando a algunas familias que no compartieran ese ideario el derecho a ejercer la elección del tipo de educación conforme a sus convicciones, pero no tiene la obligación de hacerlo cuando se produce el caso contrario, es decir, cuando existen suficientes centros públicos para escolarizar a todos los alumnos. 


\section{Gobierno del Partido Socialista Obrero Español (1982-1996)}

\section{Ley Orgánica Reguladora del Derecho a la Educación (LODE)}

La Ley Orgánica 8/1985, reguladora del derecho a la educación (LODE) de 3 de julio (BOE no 159, de 4 de julio de 1985) desarrolla el artículo 27 de la Constitución Española (CE) y su máxima aspiración fue garantizar el derecho a la educación (Puelles Benítez, 2004) y la participación en los centros, abarcando muchos más aspectos de los que trató la Ley Orgánica del Estatuto de Centros Escolares (LOECE), como las nuevas regulaciones de la financiación de los centros privados. Esta Ley, que deroga la anterior, se aprobó en 1984, pero el recurso de inconstitucionalidad, presentado por el grupo popular antes de su publicación definitiva, retrasó su entrada en vigor hasta 1985.

Los centros docentes fueron clasificados atendiendo conjuntamente a los criterios de titularidad jurídica y origen y carácter de los recursos para su sostenimiento. Introdujo de este modo la clasificación que ha perdurado hasta el momento actual (artículo 10) ${ }^{4}$.

Los centros concertados podían ser elegidos por las familias en las mismas condiciones que los públicos y debían mantener un número mínimo de alumnos por profesor para conservar el concierto. Se organizó, por tanto, un sistema de financiación en el que, como anota San Segundo, "los fondos siguen a los alumnos" (San Segundo, 2001, p. 175). Las regulaciones administrativas a las que se someten los centros concertados afectan fundamentalmente a tres ámbitos: recursos (gasto y ratio alumnosprofesor), órganos de gobierno y criterios de admisión.

En el preámbulo se afirma que la elección forma parte del contenido de la libertad de enseñanza y que no puede existir esta libertad si no se ofrecen plazas gratuitas para todos los alumnos, es decir, prevalece el derecho a la educación sobre la elección. Para garantizar ambos (derecho a la educación y derecho a elegir), las distintas administraciones se valen de una programación adecuada de los puestos escolares gratuitos (artículo 20.1), que debe tener en cuenta la oferta de centros públicos y de los privados financiados con fondos públicos (artículo 27.3). Señala también que la elección debe prolongarse en el acto de participación en el centro, dando vida "a un auténtico proyecto educativo". Esta idea unida a que la libertad de enseñanza lleva implícita la libertad de crear centros docentes y dotarlos de un proyecto educativo propio, es muy relevante y novedosa. Por un lado, el proyecto educativo es más amplio que el carácter moral del centro y, por otro, no se trata únicamente de promover la elección entre diversos proyectos, sino que dado que es una de las primeras leyes de la democracia, trata de que las familias que han elegido ese centro se comprometan en su actividad educativa, dando forma a un proyecto que represente a toda la comunidad educativa. Los centros públicos, aunque pueden desarrollar proyectos educativos propios, han de garantizar la neutralidad ideológica y el respeto a todas las opiniones religiosas y morales. De este modo, la diversidad entre los centros públicos no se basa en ninguna creencia o ideología, ya que todos ellos han de ser neutrales, pero al mismo tiempo, admite la pluralidad y diversidad dentro del centro, al ser respetuoso con todas ellas. Se repite aquí la tensión entre homogeneidad y heterogeneidad. 
De forma más concreta, el derecho a la elección de centro queda recogido en la LODE en su artículo 4 (posteriormente derogado por la Ley Orgánica de Calidad de la Educación, LOCE, en 2002). Se reconoce de este modo, la capacidad de los padres "para elegir centros docentes distintos de los creados por los poderes públicos" y "la formación religiosa y moral que esté de acuerdo con sus convicciones". Como puede comprobarse, se repite aquí sí, la interpretación restringida de la elección, al no incluir como parte de este derecho la elección de centro dentro del sector público. Sin embargo y en previsión de los posibles desajustes entre oferta y demanda de plazas en centros públicos y concertados, establece los instrumentos para llevarla a cabo (criterios de admisión en los centros). En el caso de que exista exceso de demanda (y sólo en este caso), los centros deben aplicar unos criterios determinados por la LODE para seleccionar el alumnado que se matriculará en el centro. Estos criterios están enunciados en el artículo 20.2 de la Ley y fueron desarrollados dos años más tarde por el Real Decreto 2375/1985 (analizado posteriormente). El primer criterio se basa en los niveles de ingresos de las familias; el segundo, en la situación de la residencia familiar con relación al centro (se establecen áreas de influencia reguladas también en ese Real Decreto de 1985); y el tercero, en el número de hermanos que estudian en el centro. Los centros concertados deben aplicar los mismos criterios (artículo 53), pero gozan de autonomía en este aspecto los privados no subvencionados por la administración (artículo 25).

También pueden aplicarse otros criterios complementarios, pero éstos no son fijados por ninguna ley orgánica, sino por decretos ministeriales o por las comunidades autónomas con competencias en materia de educación, y por tanto, sufren mayor variación. En algunas ocasiones, incluso, el centro puede otorgar puntuación por una circunstancia libremente apreciada por el órgano competente del centro.

Entre los criterios de admisión propuestos por la LODE hay dos muy polémicos. El primero es de la discriminación positiva o inversa (mayores posibilidades para las rentas más bajas). Muchas personas no admiten este criterio, alegando que no deja de ser discriminación y por tanto contrario a la igualdad. El segundo es de la zonificación escolar, que según los sectores más partidarios de una mayor garantía de la libertad de elección de centro, compromete esta elección. La sentencia de 1985 del Tribunal Constitucional señaló la legalidad de estos artículos, pues los mismos a su juicio, no limitan la libertad de elegir, sino que se refieren a un proceso de admisión que se realiza una vez efectuada ya la elección.

\section{Sentencia del Tribunal Constitucional 77/1985, de 27 de junio, Relativa a la Ley Orgánica 8/1985 Reguladora del Derecho a la Educación (LODE)}

La Ley Orgánica reguladora del Derecho a la Educación (LODE) recibió un recurso de inconstitucionalidad previo a su publicación contra muchos de sus artículos, lo que paralizó su promulgación hasta comienzos de julio de 1985. El Tribunal Constitucional dictó sentencia el 27 de junio de 1985 (publicada en el BOE no 170, de 17 de julio), resolviendo algunas cuestiones sobre las limitaciones de la libertad de elección de centro 
cuando la demanda supera a la oferta escolar. Constituye la primera ocasión en que el Tribunal Constitucional se manifestaba sobre esta cuestión.

El motivo primero del recurso alegaba que el artículo 20.2 (que establece los criterios prioritarios de admisión en los casos que exista un insuficiente número de plazas) y 53 (que obliga a los centros concertados a respetar los criterios anteriores) de la LODE no respetaban el contenido esencial del derecho a la libre elección de centro al establecer diferentes prioridades "carentes de justificación objetiva" que sustituyen "el juego espontáneo de la libre elección de centro por una programación pública que dejaría sin sentido tal derecho" (antecedente $5^{\circ}$ ). Esta programación se basa en el establecimiento de la zonificación escolar, que se recogía ya en la Ley Orgánica anterior, la LOECE, aunque con una formulación diferente. El Tribunal entendió que estos artículos eran respetuosos con la Constitución, principalmente porque el estado no realiza adscripciones forzosas de alumnos a determinados centros (fundamento jurídico quinto). El término admisión ya implica la existencia de una voluntad previa de la familia de acudir a ese centro. Cuando los criterios de admisión son aplicados tras la previa solicitud del interesado y sólo en caso de insuficiencia de plazas como ocurre en nuestro sistema educativo, el Tribunal entiende que se refuerza el derecho a la elección de centro, ya que los criterios objetivos impiden una selección arbitraria por parte de los centros públicos y concertados. Junto a esto, añade que la mayor o menor intensidad de la preferencia de una familia por un ideario no debe instrumentar jurídicamente un derecho constitucionalmente reconocido a ocupar una plaza en un centro (fundamento jurídico quinto).

\section{Real Decreto 2375/1985, por el que se Regulan los Criterios de Admisión de Alumnos en los Centros Sostenidos con Fondos Públicos}

El Real Decreto 2375, de 18 de diciembre de 1985 (BOE no 310, de 27 de diciembre), fue elaborado para desarrollar los artículos 20.2 y 53 de la LODE. Fue la primera regulación, tras esta Ley Orgánica, de los criterios de admisión que establecían la prioridad en el acceso a los centros públicos y concertados. El Real Decreto estableció una serie de principios y requisitos que debían respetarse en todo proceso de admisión. Aún no se había producido el traspaso de competencias en materia educativa a todas las comunidades autónomas (sólo estaba completado en Andalucía, Canarias, Cataluña, Galicia, País Vasco y Valencia), por lo que este Real Decreto era de aplicación en prácticamente todo el territorio español. Una vez concluido ese proceso de transferencia de competencias, cada administración autonómica tiene capacidad para regular sus propios procesos de admisión y para establecer el peso de cada criterio de admisión regulado en las leyes orgánicas estatales.

Los criterios y su valoración objetiva sólo habían de aplicarse en el supuesto de que no hubiese en los centros solicitados un número de plazas suficiente para atender todas las demandas de ingreso. La justificación para incluir la puntuación de cada criterio responde a la necesidad de garantizar el derecho a la elección de centro impidiendo la selección arbitraria por parte de éstos. Junto a este derecho a elegir centro público o privado (artículo 2) se reguló expresamente (artículo 4) la prohibición de condicionar la admisión al resultado de exámenes o pruebas de ingreso en el centro y de discriminar en el acceso por razones ideológicas, religiosas, morales, sociales, de raza o nacimiento (artículo 5). 
En la aplicación del criterio de proximidad se permitió considerar el lugar de trabajo de los padres como domicilio, siempre que a juicio de los órganos competentes en la admisión existiera causa justificativa para ello (artículo 9.2). En los decretos posteriores se suprimió la necesidad de autorización administrativa para equiparar el lugar de trabajo al domicilio familiar a efectos de admisión. La determinación de las áreas de influencia de los centros ha sido siempre la parte más polémica de los procesos de admisión. El único requisito es que cualquier domicilio quede comprendido en al menos el área de influencia de un centro.

El criterio de renta y el de proximidad están valorados con el mismo peso, representando ambos, en caso de obtener puntuaciones máximas, el $40 \%$ de la valoración que recibe un alumno en este apartado.

Los criterios complementarios ${ }^{5}$ han mostrado desde el principio una amplia variedad en su redacción. Este primer Decreto incluyó los siguientes (artículo 11): condición de emigrante retornado del alumno o de sus padres o tutores en los tres últimos años (1 Punto); existencia de minusvalías físicas, psíquicas o sensoriales del alumno, de los padres o hermanos del mismo en edad escolar (1 Punto); situación de familia numerosa (1 Punto); cualquier otra circunstancia libremente apreciada por el órgano competente del Centro de acuerdo con criterios objetivos (1 Punto).

\section{Ley Orgánica de Ordenación General del Sistema Educativo (LOGSE)}

La LOGSE (Ley Orgánica 1/1990 de Ordenación General del Sistema Educativo) fue aprobada el 3 de octubre de 1990 (BOE no 238, de 4 de octubre de 1990) y plantea una reforma estructural pero también reformas curriculares. Del mismo modo, trató varios aspectos organizativos que determinan la amplitud o limitación de la autonomía, la diversidad, e incluso la admisión en determinadas enseñanzas.

Uno de los factores de calidad reconocidos en la ley es la programación docente, realizada por los propios centros, que deben completar y desarrollar el curriculum propio de cada nivel, etapa, ciclo, grado y modalidad redefiniéndolo para adaptarlo a su situación. Los centros gozan de autonomía pedagógica, organizativa y de gestión, dentro de la legalidad marcada por las disposiciones que han desarrollado la LOGSE. Dentro de este marco de autonomía, cada centro debe realizar un proyecto pedagógico que le identifique con unos criterios educativos específicos.

Por primera vez se habla de diversidad en la normativa legal. En el preámbulo se reconoce la necesidad de la diversidad, especialmente en secundaria, para poder adaptarse a los distintos intereses de los alumnos y al contexto social en el que se enmarca el centro. Sin embargo, aunque los centros educativos gozan de autonomía en la definición y programación de las materias optativas (artículo 21.3), el desarrollo reglamentario posterior fue muy restrictivo con estas asignaturas, las únicas en las que podía reflejarse algún atisbo de diversidad. A pesar de estos cambios, de nuevo, como ya ocurrió con la LODE, esta diversidad y pluralidad sólo se encuentra dentro de cada centro docente ${ }^{\text {vi }}$ (en la LODE se hablaba de la neutralidad de los centros que acogían pluralidad de creencias e intereses) y no se da pie al desarrollo de proyectos curriculares que amplíen la diversidad de la oferta educativa con diferencias que lleguen más allá de las materias optativas o las actividades que desarrollen el curriculum. Se insiste, además, 
en la importancia de un curriculum común y en la enseñanza comprensiva, términos que tradicionalmente se consideran en contradicción con la diversidad de oferta pedagógica. Pero en realidad, a pesar de las posibilidades permitidas a las comunidades y a los propios centros para adaptar su enseñanza a las características del entorno, no se habla en ningún momento de la singularidad de los centros públicos, sino que se insiste en su cuerpo común, como si ambos fueran incompatibles. Quizá, la enseñanza comprensiva puede utilizarse como punto de partida para crear esa diversidad pedagógica que está necesitando el sistema educativo.

\section{Real Decreto 377/1993 por el que se Regula la Admisión de Alumnos en Centros Sostenidos con Fondos Públicos de Educación Infantil, de Educación Primaria y de Educación Secundaria}

Entre los objetivos declarados en el preámbulo del Real Decreto 377/1993, de 12 de marzo (BOE no 71, de 24 de marzo), se encuentran la de crear comisiones que se encarguen de asesorar a padres y alumnos sobre las posibilidades de escolarización y que colaboren en la gestión del proceso de admisión y, por último, el deseo de dar más valor al criterio de proximidad. Esta decisión se justifica, según el Ministerio, por la existencia de un número suficiente de plazas escolares para atender a todas las necesidades.

Por primera vez se permite la posibilidad de adscribir ${ }^{7}$ centros de primaria a institutos de educación secundaria, en proporción uno a uno. En el caso de los concertados, la adscripción se realizaría a petición del titular y preferentemente entre aquellos centros que se encuentren en el mismo recinto escolar o que pertenezcan al mismo titular. Para acceder al instituto de secundaria al que está adscrito su centro de primaria, los alumnos no necesitan un nuevo proceso de admisión. De este modo, se reducen notablemente las ocasiones en que se aplican los criterios de admisión y las ocasiones en las que una familia se replantea el centro que desea elegir para sus hijos, dada la escasez de posibilidades de ser admitido en un centro no adscrito. En cierto modo se limita el derecho de elección de las familias, ya que elegir un centro de primaria supone en la práctica elegir anticipadamente uno de secundaria que quizá no responde a sus intereses.

Se mantuvieron los mismos criterios prioritarios del anterior decreto de 1985, aplicados sólo en casos de exceso de demanda, aunque con puntaciones y peso muy diferente. A consecuencia del malestar existente en las grandes ciudades por la aplicación práctica del criterio de renta reducida, se optó por modificar las valoraciones para primar el criterio de distancia sobre el de renta (San Segundo, 2001, p. 177). El criterio de renta pasó a representar únicamente el $20 \%$ de la puntuación total, frente al peso del $50 \%$ de la distancia al centro y el 30\% del criterio de hermanos matriculados. Estos cambios hicieron altamente improbable elegir un centro fuera de la correspondiente zona de influencia. El lugar de trabajo de los padres se consideró equivalente, a instancia del solicitante, para la admisión en los centros de enseñanzas obligatorias y no obligatorias, respectivamente (artículo 12.3).

Se suprimieron los criterios complementarios, considerando sólo el supuesto de solicitantes que padecieran minusvalías físicas, psíquicas o sensoriales, lo que permitía 
añadir un punto adicional a los ya obtenidos de la aplicación de los criterios prioritarios (artículo 14).

En caso de empate el artículo 15 marca el orden que se ha de seguir para proceder al desempate entre los solicitantes: mayor puntuación obtenida en el apartado de proximidad domiciliaria; mayor puntuación obtenida en el apartado de hermanos matriculados en el centro; situación de minusvalía valorada junto a los criterios prioritarios. Las instrucciones para el procedimiento de desempate son muy indicativas del valor que se concede a cada criterio en las distintas regulaciones. En este caso, podemos comprobar cómo, además de considerar a la proximidad como el más importante, la renta ni siquiera aparece valorada como criterio de desempate, lo que muestra el poco valor que se le concedió.

Otra de las novedades de este Decreto es la creación de Comisiones de Escolarización por las Direcciones Provinciales del Ministerio de Educación, compuestas por representantes de los centros implicados, el Servicio de Inspección, los ayuntamientos y las asociaciones de padres. Estas comisiones fueron creadas a imagen y semejanza de las existentes en otros países europeos pero en nuestro sistema educativo no han adquirido un peso tan relevante, sino que son consideradas como un órgano burocrático y al servicio de la administración en lugar de al servicio de la comunidad educativa como fuente de información sobre centros y vacantes. De hecho, sus funciones (artículo 17.2) son tan relevantes como informar a los padres o tutores y a los alumnos sobre los centros sostenidos con fondos públicos y sobre las plazas disponibles en los mismos o escolarizar a los alumnos que no hayan obtenido plaza en el centro solicitado. En este caso, deben exponer a los padres o tutores o a los alumnos la relación de los centros, con plazas vacantes, para que opten por alguna de ellas. Son también los responsables de decidir, oídos los sectores afectados, en especial los padres o tutores de los alumnos, sobre la escolarización de los alumnos con necesidades educativas especiales y los pertenecientes a minorías cuyas condiciones sociales y culturales dificulten su integración escolar. La decisión sobre esto puede ser adoptada en un momento anterior a la determinación de las vacantes de los centros, y ha de tender a lograr una efectiva integración de los alumnos aludidos. El permitir a la Comisión determinar la escolarización en un centro sin que éste haya notificado las plazas vacantes, es otro de los aspectos criticados, especialmente por los concertados.

\section{Ley Orgánica de la Participación, la Evaluación y el Gobierno de los Centros Docentes (LOPEG)}

La LOPEG, Ley Orgánica 9/1995, de 20 de noviembre, de la Participación, la Evaluación y el Gobierno de los Centros Docentes (BOE no 278, de 21 de noviembre de 1995), reforma la LODE y algunos aspectos de la LOGSE. Es una Ley que trata de impulsar la autonomía de los centros unida a la participación, profesionalización y la evaluación. En ella subyace la idea de que la autonomía implica mayor profesionalización pero también mayor control y evaluación.

En el preámbulo, la LOPEG señala la necesidad de cumplir con una adecuada participación, autonomía y organización de los centros que garantice la ausencia de discriminación en la elección de centro. Como ha ocurrido con todas las leyes aprobadas durante el periodo legislativo del PSOE, la libertad de elección de centro 
preocupa más en tanto no produzca ninguna discriminación entre los alumnos que en lo relativo a la posibilidad de elegir entre mayor o menor oferta educativa.

En el Título I "De la participación de la comunidad educativa en la organización y gobierno de los centros docentes sostenidos con fondos públicos y en la definición de su proyecto educativo", el Capítulo segundo "De la autonomía pedagógica organizativa y de gestión de los recursos de los centros educativos", se dedica al establecimiento de los límites de la autonomía de los centros en sus distintas vertientes. La autonomía de gestión se concreta en la elaboración mediante el proyecto educativo y curricular de un modelo de gestión organizativa y pedagógica. El artículo 6 regula la elaboración de estos proyectos que deben recoger los objetivos, prioridades y procedimientos de actuación del centro, teniendo en cuenta las características del entorno y las necesidades específicas de los alumnos. Este proyecto educativo ha de ser público y las administraciones educativas deben colaborar con los centros para que éstos también den publicidad a otros aspectos que proporcionen información y orientación a los alumnos y padres, favoreciendo mayor implicación de la comunidad educativa. El proyecto educativo de los centros concertados puede incluir su carácter propio. Toda la autonomía pedagógica concedida a los centros públicos se basa en la filosofía de que éstos han de adaptarse lo mejor posible a su entorno, pero no en la posibilidad de que desarrollen su propio proyecto educativo (metodológico, curricular, organizativo, etc.) más allá de las simples adaptaciones curriculares.

La Ley dedica todo el Título III a la evaluación, el tercer pilar (junto a la participación y la autonomía) del sistema educativo tras la aprobación de la LOPEG. Además, el Gobierno ha de hacer públicos las conclusiones de interés general de las evaluaciones llevadas a cabo por el INCE (no todos los resultados obtenidos en las mismas) y los indicadores de calidad establecidos. Este tipo de evaluación a través de indicadores fácilmente comparables provocó muchas suspicacias entre algunos sectores de la enseñanza que pensaron que esta medida se encaminaría hacia la elaboración de un ranking en el que se compararía a los centros, clasificándolos en categorías de calidad. Desde muchos sectores se creyó que esta Ley sería el primer paso hacia la libertad de elección de centros ${ }^{8}$, ya que la implantación de los sistemas de evaluación (junto con la repercusión de la evaluación docente en su carrera profesional), la profesionalización, y la obtención de recursos extras, podrían dirigir el sistema hacia la competencia entre los centros por la obtención de alumnos. A la larga, se ha demostrado que esto no fue así. Quizá simplemente porque estas medidas no han cuajado en el sistema educativo o quizá porque no era su pretensión real.

\section{Gobierno del Partido Popular (1996-2004)}

Con la victoria del Partido Popular, la elección de centros se convirtió en uno de los objetivos de la política educativa nacional. Sin embargo, no se acompañó de reformas reales que pudieran utilizar esta elección como un instrumento de innovación o de mejora educativa. Se mantuvieron la zonificación y la excesiva limitación de la autonomía de los centros. Se introdujeron conceptos (como la competencia entre centros) pero las reformas fueron llevadas a cabo sin un fundamento pedagógico que les 
diera sentido. Si este era el objetivo, el medio era "la programación de la enseñanza". Para la Ministra, el gobierno socialista había confundido el medio con el objetivo y viceversa. Del mismo modo, manifestaba la necesidad de que el sistema educativo se ajustara a la demanda de plazas, ampliando las zonas de admisión, autorizando más aulas en los centros de mayor demanda de plazas y anunciando medidas correctivas en los centros públicos que no lograran atraer un número suficiente de alumnos. Todas estas medidas se correspondían, sin duda, con muchas de la reformas introducidas en 1988 en el Reino Unido por Margaret Thatcher. Se intentó hacer efectivo el principio de la calidad a través de la libertad de elección de centros. La calidad, afirmaba, debía medirse por los resultados. Una vez medidos los conocimientos se conocerá la calidad que ofrecen los centros, los padres conocerán la mejor escuela y los establecimientos de enseñanza competirán por conseguir el mayor número de alumnos.

\section{Real Decreto 366/1997 por el que se Regula el Régimen de Elección de Centro Educativo}

El Real Decreto 366/1997, de 14 de marzo (BOE no 64, de 15 de marzo) fue el primero en materia de admisión aprobado por el gobierno del Partido Popular, y el último sobre elección escolar elaborado por un gobierno central hasta la fecha, ya que tras su aprobación se completó el traspaso de competencias en educación a todas las comunidades autónomas y desde entonces son estas administraciones quienes se encargan de regular el proceso. Este Decreto se denominó "regulador de la elección” en lugar de "regulador de la admisión” como se había hecho hasta entonces. En el preámbulo se señala la necesidad de una nueva normativa para evitar que las exigencias de la planificación constriñeran la libertad de elección de centro hasta el punto de hacerla inefectiva.

Los objetivos propuestos para favorecer la amplitud de la referida libertad de elección, fueron: ampliar las zonas de influencia designadas para cada centro; definir el criterio de proximidad referido indistintamente al domicilio o al lugar de trabajo de los padres ${ }^{9}$; introducir criterios complementarios que combinasen el carácter social con la competencia entre centros; reforzar el valor del criterio prioritario de tener hermanos matriculados en el centro; permitir a las familias participar en el proceso de elección conservando al mismo tiempo, la prioridad de la plaza que les correspondiese por la vía de la adscripción; establecer la posibilidad de adscripciones múltiples entre centros de primaria y secundaria.

Todos los objetivos anteriores responden, sin ninguna duda, a una política desreguladora con la intención de fomentar la competencia entre centros y aumentar el número de opciones disponibles (de entre las ya existentes, sin favorecer la creación de opciones diversas) para las familias: mayor número de centros adscritos a la escuela de primaria, domicilios pertenecientes a más de una zona de influencia de centros, adscripción no determinante de la elección de los padres en primaria pero con la seguridad de no quedarse sin plaza en el centro más cercano, etc. En realidad, este tipo de políticas desarrolladas al margen de cualquier otra actuación dirigida a la diversidad de la oferta o las posibilidades de información de las familias ${ }^{10}$, no producen ningún efecto en la dirección pretendida, como de hecho ocurrió en el sistema educativo español. 
Se respetaron los mismos criterios prioritarios y se incorporaron de nuevo algunos criterios complementarios, aplicados con carácter concurrente. Se mantuvo la puntuación asociada a la renta y se elevó el peso de la presencia de los hermanos en el mismo centro.

Los criterios complementarios fueron: situación de familia numerosa; condición reconocida de minusválido físico, psíquico o sensorial de los padres, o hermanos del alumno, o en su caso del tutor; cualquier otra circunstancia libremente apreciada por el órgano competente del centro de acuerdo con criterios objetivos que deberán ser hechos públicos por los centros con anterioridad al inicio del proceso de admisión. Este último precepto suscitó, de modo sorprendente, gran controversia, ya que según sus críticos, dejaba en manos de los centros las decisiones de admisión en numerosos casos de empate entre solicitantes, y abría la puerta a la utilización de criterios académicos en las admisiones (San Segundo, 2001, p. 178). Lo cierto es que como criterio complementario ya aparecía en el Real Decreto 2375/1985 (comentado en el punto 2.3.- de este artículo) aprobado en la legislatura socialista.

Los empates se resolvieron aplicando, en este mismo orden y hasta que se diese el desempate, los siguientes criterios: mayor puntuación obtenida en el apartado de hermanos matriculados en el centro; mayor puntuación obtenida en el apartado de proximidad domiciliaria; menor renta anual per cápita en la unidad familiar; asignación por sorteo. De nuevo, los criterios de desempate nos proporcionan una información muy útil sobre la consideración que el Ministerio otorgó a cada uno de los criterios prioritarios. A pesar de no dar demasiado valor al criterio de la renta, el gobierno del Partido Popular lo recuperó como criterio de desempate, tras su eliminación en el Decreto socialista anterior.

\section{Ley Orgánica de Calidad de la Educación (LOCE)}

La Ley Orgánica 10/2002, de 23 de diciembre, de Calidad de la Educación (LOCE), fue publicada en el Boletín Oficial del Estado de 24 de diciembre del mismo año. Su objetivo fundamental, según se declara en la propia Ley, es el "logro de una educación de calidad para todos".

Uno de los ejes en los que la ley sustenta la calidad es la mayor orientación hacia los resultados, apoyándose en la implantación de mecanismos de evaluación, que afectan al aprendizaje, a los centros, a los profesores, al sistema, etc. Más concretamente, la Ley prevé que al finalizar la educación primaria y la educación secundaria obligatoria se realice una "evaluación general de diagnóstico", sin efectos académicos y cuya finalidad es proporcionar a la Administración, los colegios, las familias y los alumnos información sobre la consecución de los objetivos ${ }^{11}$. Esta información introduce en el sistema la posibilidad de comparar los resultados de los centros y utilizar esta información en la decisión de la elección de centro.

La libertad de elección de centros es reconocida como uno de los derechos de los padres en el artículo 3, junto con el derecho a que sus hijos reciban la formación religiosa y moral de acuerdo con sus convicciones ${ }^{12}$. Del mismo modo, afirma en el artículo 72 que la planificación de los puestos escolares debe garantizar "la efectividad 
del derecho a la educación" así como "el derecho a la libre elección de centro".Las distintas medidas para garantizar la libertad de elección de centros se inscriben dentro del quinto eje de calidad, concretamente en el Título V, "De los centros docentes". Algunas de estas medidas se centran en el aumento de la diversidad de la oferta educativa a través del reconocimiento de centros con especialización curricular (artículo 66). Esta modificación curricular puede referirse a los ámbitos lingüístico, humanístico, científico, tecnológico, artístico, deportivo y de las tecnologías de la información y de las comunicaciones. La autonomía de estos centros es parcialmente más amplia que la de los ordinarios, pudiendo por ejemplo ampliar los horarios lectivos para desarrollar su proyecto de especialización. Desde el punto de vista pedagógico, esta propuesta es la más comprometida con la libertad de elección de toda la historia de nuestra legislación educativa, al menos una vez desarrollado el sistema de financiación de centros privados. Este artículo introduce la posibilidad de aumentar radicalmente la diversidad de la oferta educativa. En la práctica, al referirse únicamente a los contenidos curriculares olvidando otras posibilidades de agrupamientos de alumnos y metodologías, la especialización curricular no va a diferir mucho de los centros que anteriormente habían desarrollado su propio proyecto educativo centrado en alguna temática específica vinculada a su contexto más cercano (educación en valores, integración, centros bilingües, etc.), pero aún así, es la primera vez que se legisla (además con rango de ley orgánica) esta posibilidad de desarrollar la especificidad de un centro público y reconocerlo en su propia denominación.

La ley también regula en la disposición adicional quinta los criterios de admisión que deben ser aplicados en los centros sostenidos con fondos públicos en caso de no existir plazas suficientes ${ }^{13}$. Los criterios prioritarios señalados son: renta per cápita de la unidad familiar; proximidad del domicilio; existencia de hermanos matriculados en el centro; concurrencia de discapacidad en el alumno o en alguno de sus padres o hermanos; condición legal de familia numerosa; concurrencia en el alumno de enfermedad crónica que afecte al sistema digestivo, endocrino o metabólico. Para las enseñanzas no obligatorias, se podrá considerar además el expediente académico. Los centros con especialización curricular podían añadir criterios complementarios relacionados con la especificidad de su oferta, lo que refleja su mayor capacidad de autonomía organizativa y de gestión. Hasta el momento, ningún centro podía aplicar sus criterios de admisión; la máxima autonomía concedida por las administraciones autonómicas era otorgar un punto a los alumnos que cumplieran determinado requisito (por ejemplo ser hijo de un trabajador del centro).

Esta regulación de la admisión introduce varias novedades con respecto a las anteriores leyes orgánicas, a pesar de que respeta la consideración de los tres criterios prioritarios establecidos por la LODE en 1985 (renta, proximidad al centro y hermanos matriculados en el mismo). Por un lado, añade la posibilidad de que los centros que imparten enseñanzas no obligatorias consideren el rendimiento académico en la selección de alumnos. Hasta este momento, ninguna ley orgánica había considerado este criterio como tal, aunque se había regulado al redactar los requisitos de acceso a la formación profesional (no al bachillerato). Por otro, incluye la consideración de las 
situaciones de discapacidad, familia numerosa o enfermedad crónica ${ }^{14}$ como criterios prioritarios, cuando en anteriores ocasiones únicamente se habían añadido como criterios complementarios en órdenes ministeriales o Decretos de admisión de las Comunidades Autónomas. Otra de las modificaciones que cambia de forma relevante el proceso de admisión en los centros es la adscripción entre centros de educación infantil y centros de primaria. Esta nueva vinculación entre centros no sigue la misma línea que el resto de la ley, puesto que como ya se comentó en páginas anteriores, las adscripciones entre centros no hacen sino reducir las posibilidades de elección de las familias al cambiar de nivel educativo. Hay que tener presente, además, que la LOCE introduce los conciertos en Educación Infantil, por lo que en los concertados cabe la posibilidad de que la selección de alumnos se realice en Infantil y cubra ya todos los niveles concertados hasta el final de la enseñanza obligatoria.

\section{Gobierno del Partido Socialista Obrero Español (2004-2007)}

\section{La Ley Orgánica de Educación}

La última ley orgánica reformadora del sistema educativo fue la Ley Orgánica 2/2006 de 3 de mayo de Educación (B.O.E. no 106, de 4 de mayo).

Esta normativa insiste de nuevo en la importancia de que los centros elaboren sus proyectos pedagógicos intentando adecuar su actuación a las circunstancias concretas de su situación y su alumnado y las únicas modificaciones curriculares que permite son las relacionadas con el establecimiento de materias optativas. La elección por parte de los alumnos se dirige fundamentalmente a las preferencias que muestran por determinadas modalidades de bachillerato o selección de materias optativas. En el preámbulo se señala cómo el modelo de programación de la enseñanza respeta el derecho a la educación y la libertad de enseñanza, pero no introduce la libertad de elección como uno de sus objetivos. La primera referencia a la elección de centro la encontramos en el Título II "Equidad en educación", Capítulo III "Escolarización en centros públicos y privados", cuando el artículo 84 expone los requisitos y procesos que caracterizan la admisión de alumnos. En la redacción de este artículo sorprenden dos cosas. Por un lado, se encuentra situado dentro de un título que habla de equidad, a la que da prioridad sobre la elección en todo el desarrollo de la ley. Por otro y relacionado con el aspecto anterior, añade a la redacción tradicional de la normativa sobre admisión, que recoge la necesidad de garantizar tanto el derecho a la educación como la libertad de elección, el acceso en condiciones de igualdad. Esta insistencia se debe a la postura que ha tomado el Partido Socialista en los últimos años sobre el reparto de alumnos con necesidades educativas especiales (principalmente inmigrantes), basada en una crítica vertida sobre las políticas de admisión que estaban conduciendo a una concentración excesiva de alumnado inmigrante en los centros públicos, frente al pequeño porcentaje asumido por los concertados. En la lucha contra las diferencias encontradas en el alumnado matriculado entre los dos tipos de centros, se introdujeron en la ley dos nuevos artículos (86 y 87) cuyos objetivos son asegurar la igualdad en la aplicación de 
las normas de admisión y el equilibrio en la admisión de alumnos con necesidades específicas de apoyo educativo en todos los centros de la red de centros escolares sostenidos con fondos públicos.

Los criterios prioritarios aplicados cuando no existan plazas suficientes para todo los alumnos se basan en los que estableció la LODE en el año 1985, con alguna pequeña variación: existencia de hermanos matriculados en el centro o padres o tutores legales que trabajen en el mismo, proximidad del domicilio o del lugar de trabajo de alguno de sus padres o tutores legales, rentas anuales de la unidad familiar, atendiendo a las especificidades que para su cálculo se aplican a las familias numerosas, y concurrencia de discapacidad en el alumno o en alguno de sus padres o hermanos. Quizá la principal modificación se encuentra en que lo que algunos centros solían introducir como una de las circunstancias libremente apreciadas por el órgano competente (padres o tutores trabajadores en el mismo como criterio complementario que las administraciones autonómicas permitían que el centro elaborara por sí mismo) se ha transformado en un criterio prioritario de obligado cumplimiento en todo el territorio español. Además, el criterio de renta está influido por la condición de familia numerosa y la situación de discapacidad se mantiene como en la LOCE, es decir, como criterio prioritario.

La calidad y la evaluación son también dos aspectos fundamentales de la reforma. Se proponen pruebas de diagnóstico de las competencias básicas que realiza el propio centro en cuarto de primaria y segundo de ESO. Se aclara de forma expresa que estos resultados deben ser "formativos y orientadores para los centros e informativos para las familias" (artículos 21 y 29) y en ningún caso, utilizarse "para el establecimiento de clasificaciones de los centros" (artículo 144.3). El Ministerio pretende con esta afirmación desligarse de las concepciones que vinculan la evaluación con la elaboración de un ranking de centros y la introducción de filosofías de mercado en los sistemas educativos. En realidad, establecer una clasificación de centros valorando únicamente la competencia curricular de sus alumnos, sin considerar el valor añadido de la escuela y sobre todo, sin permitir a las familias que elijan el centro que desean para sus hijos no sirve, desde el punto de vista educativo, para nada.

Aunque en el documento presentado en septiembre de 2004 con el nombre "Una educación de calidad para todos y entre todos. Propuestas para el debate", que había de servir de base para el comienzo de la reforma de la enseñanza había una clara intención de incentivar y motivar la especificidad de los centros (MEC, 2004), en la redacción final de la ley no encontramos tal apoyo. Podemos encontrar un pequeño reconocimiento a los proyectos pedagógicos de los centros como el documento que les identifica, cuando en el artículo 84.9 se determina que en el momento en que un alumno se matricula en un centro está aceptando tal proyecto, cuando las normativas previas se limitaban a tratar la aceptación del ideario o del carácter propio del centro. De hecho, el artículo 121 dispone que el proyecto educativo de los centros concertados incorporará el carácter propio de los mismos. De nuevo se toma partido por configurar centros y aulas que reflejen la pluralidad de la sociedad española evitando la creación de centros especializados que agruparan a los alumnos por otro criterio que no fuera la proximidad al mismo. 


\section{Conclusiones}

Esta breve revisión sobre la definición de la libertad de elección a través de la política educativa española, ha intentado ofrecer un análisis pedagógico de la evolución jurídica de este concepto. Como se ha podido comprobar, la elección en el sistema educativo español ha recibido siempre una interpretación muy reduccionista, sobre todo en dos aspectos. Por un lado, las referencias normativas habituales sobre las opciones entre las que pueden elegir las familias, se centran en "el tipo de formación moral y religiosa de acuerdo a sus convicciones", o en elegir entre un centro privado o uno público. Por otro, no se ha permitido que los centros escolares tengan la autonomía suficiente para comprometerse con un proyecto pedagógico elegido por el propio claustro.

En realidad, la elección en educación no puede ser desarrollada al margen de otros aspectos. Para que elegir tenga sentido, debe existir cierta diversidad entre la que seleccionar la opción más adecuada. Para que los centros puedan trabajar en la elaboración de un proyecto educativo que los identifique es imprescindible un grado mayor de autonomía (pedagógica, organizativa y de gestión) de la que gozan en la actualidad. Todos estos factores pedagógicos que acompañan a la elección no han sido tratados aquí en profundidad por motivos de espacio. En cualquier caso, no hay que olvidar que las políticas de elección pueden y deben ser utilizadas como instrumento para lograr otros objetivos educativos (lo que ha tenido consecuencias muy favorables) y no como un objetivo en sí mismo (los resultados en este sentido han sido muy dispares en otros sistemas escolares).

El sistema educativo español no ha promovido en ningún momento de su historia la diversidad y especificidad de los centros (la defensa de la diversidad de la oferta no se puede sustentar en un sistema de itinerarios o de optatividad), a pesar de que no habría de suponer tampoco una ruptura total con la comprensividad tradicional de nuestro sistema. Se ha preferido apoyar la idea de escuelas homogéneas entre sí, albergando dentro de ellas un alumnado representativo de la diversidad social. Quizá desde el punto de vista pedagógico una combinación de ambas propuestas sea la más adecuada, es decir, pueden coexistir centros sin ninguna especialización curricular, metodológica, peculiaridad organizativa o confesión religiosa determinada, con centros que prefieran diseñar un proyecto pedagógico en torno a cualquiera de esos aspectos, atrayendo a un sector social que comparta el interés en ello. Esta última posibilidad permitiría hacer extensiva la elección de centros más allá de las convicciones religiosas, dando entrada a las opciones pedagógicas o curriculares que tanto se han echado en falta en el desarrollo del sistema educativo de los últimos 30 años.

A pesar de ese apoyo histórico a la homogeneidad de los centros, el criterio actual de selección de alumnos puede llegar a ser mucho más divisor de lo que en un inicio se pretendió. La agrupación actual en los centros está basada en el criterio confesional o laico, o en el criterio de proximidad al centro. Este criterio es más segregador que cualquiera de los utilizados en centros especializados curricular o metodológicamente ya que la segregación social se identifica muy claramente (sobre todo en las grandes ciudades) con la segregación residencial y ésta se reproduce en los propios centros. De este modo, el carácter identitario de nuestras escuelas se basa en su alumnado y no en su 
oferta educativa inicial. En España la única especificidad real hasta la LOCE (donde se permite la existencia de centros especializados curricularmente) había sido la introducida por la definición del carácter propio de los centros privados con ideario, que recoge más principios morales o religiosos que pedagógicos. Fuera de nuestras fronteras, la diversidad de los centros ha ido ya mucho más allá de la circunstancia religiosa o laica de una escuela. Haría falta una investigación centrada en la causa de la ausencia de un mayor número de centros que buscan identificarse con proyectos pedagógicos concretos; es difícil comprender por qué, junto a la enorme extensión actual de centros bilingües, no han tenido cabida otros tipos de centros especializados quizá en ciencias, deportes, etc. Sin duda la falta de tradición de verdaderas innovaciones y la excesiva homogenización de la escuela española han contribuido a evitar que se produzca esta diversidad, cuando en realidad la respuesta educativa más adecuada a una sociedad plural, puede ser una oferta también diversa. No hay que olvidar, sin embargo, a todos los centros que durante años han desarrollado proyectos que configuraron una identidad propia, con sus profesores como los verdaderos impulsores. Pero al no formar parte de la misión y visión pedagógicas compartidas por la comunidad educativa, se convierten en proyectos aislados a los que resulta difícil dar una continuidad. Esa posibilidad ha de reflejarse en las leyes, de tal modo que los centros adquieran una verdadera autonomía para organizar sus horarios, gestionar sus recursos e incluso, administrar su equipo docente. Una de las grandes demandas en nuestro sistema educativo es aumentar la autonomía del centro en la gestión del personal para garantizar la estabilidad del claustro en el marco de proyectos educativos plurianuales, así como dotarle de la capacidad de decisión para organizar el trabajo de los docentes.

Una de las principales limitaciones normativas en la elección, junto con la determinación de los criterios de admisión, son las adscripciones entre centros de diferentes niveles de enseñanza. En virtud del principio de continuidad, se ha reducido el número de veces que una familia puede elegir centro docente, lo que también puede reducir el número de ocasiones en que se interesan por la búsqueda del proyecto que mejor responde a sus convicciones, intereses y principios, ya que es prácticamente imposible acceder a un centro no adscrito en determinados niveles. 


\section{Notas}

1 Ver por ejemplo: Duru-Bellat, M. (2004); Llorent Bedmar, V. (2004); Villamor Manero, P. (2007).

2 El artículo 27 se encuentra en el título I, Capítulo II, Sección 1a "De los derechos fundamentales y las libertades públicas", aunque, a juicio de muchos autores, debió incluirse en la sección segunda "De los derechos y libertades de los ciudadanos" o en el Capítulo $3^{\circ}$ "De los principios rectores de la política social y económica", donde se incluyen derechos sociales como el derecho a la salud, seguridad social, vivienda, acceso a la cultura, etc. Argumentan en este sentido, además del autor referenciado Nogueira (1988) y Rodríguez Coarasa (1998).

3 Artículo 13.4 del Pacto Internacional de Derechos Económicos, Sociales y Culturales de 1966. El Tribunal Constitucional se refirió a esta cuestión en la Sentencia 77/1985, de 27 de junio.

4 Esta afirmación puede estar justificada jurídicamente, pero no es tan clara desde el punto de vista pedagógico. En mi opinión, una de las grandes equivocaciones en la consideración de la libertad de elección, es suponer que las familias que eligen centros públicos o privados con filosofías o idearios más diluidos o incluso sin ellos, no están eligiendo racionalmente. Quizá, y aplicando esta idea al contexto español que ahora nos encontramos analizando, seleccionar un centro público es coherente con las ideas filosófico- políticas de esa familia, que desestima de entrada todos los centros privados por convicciones personales.

5 El artículo 10 de la LODE establecía que los centros docentes podían ser públicos o privados. Los públicos son los de titularidad pública y los centros privados, funcionan en régimen de mercado, mediante precio, y dentro de éstos, se encuentran los privados concertados (subvencionados por la administración a cambio de estar sujetos a algunos controles y requisitos determinados por la ley).

6 Los criterios prioritarios han de ajustarse a lo regulado en la LODE y los complementarios aparecieron por primera vez en este Real Decreto. Ambos tipos deben aplicarse, en cualquier caso, con carácter concurrente.

7 En el mismo preámbulo se hace referencia a la necesidad de una educación que tenga sentido en una sociedad plural: "El objetivo primero y fundamental de la educación es el de proporcionar a los niños y a las niñas, a los jóvenes de uno y otro sexo, una formación plena que les permita conformar su propia y esencial identidad, así como construir una concepción de la realidad que integre a la vez el conocimiento y la valoración ética y moral de la misma. Tal formación plena ha de ir dirigida al desarrollo de su capacidad para ejercer, de manera crítica y en una sociedad axiológicamente plural, la libertad, la tolerancia y la solidaridad" (párrafo 2). En toda la Ley subyace esta idea de la necesidad de crear centros homogéneos entre sí y heterogéneos en su interior.

8 La adscripción entre centros comenzó con este Real Decreto y se ha mantenido, incluso mediante leyes orgánicas, hasta la actualidad. Esta vinculación concede prioridad sobre el resto a los alumnos de primaria que solicitan ser admitidos en el centro adscrito de secundaria obligatoria.

9 Gimeno (1996 citado en Vázquez Recio, 1999, p. 13) afirmó que esta Ley daba "pie a establecer una conexión entre la evaluación de centros y una mayor posibilidad de que os padres elijan centro público".

10 En una entrevista concedida a Cuadernos de Pedagogía en febrero de 1997, la Ministra de Educación de ese año, Esperanza Aguirre, afirmaba que uno de los objetivos para esa legislatura era "favorecer la libertad de elección de centro por parte de las familias" (1997, p. 10). Entrevista publicada en Cuadernos de Pedagogía, 255, 8-14.

11 En realidad la inclusión de este objetivo era más retórica que innovadora porque como ya hemos visto en el análisis del anterior Real Decreto sobre admisión, el lugar de trabajo de los padres ya puntuaba con el mismo valor que el domicilio familiar. 
12 Las Direcciones Provinciales, con la colaboración de los ayuntamientos, están obligadas por el artículo 5 a proporcionar información objetiva sobre los centros escolares sostenidos con fondos públicos; sin embargo son contadas las excepciones en las que se han tomado medidas serias al respecto.

13 Estas evaluaciones fueron propuestas por primera vez por la LOPEGCE en 1995.

14 Desde que lo hiciera la LOECE, esta ha sido la primera ley orgánica que ha reconocido expresamente la libertad para elegir un centro. En la LODE se reconocía a los padres el derecho a escoger un centro distinto de los creados por los poderes públicos (artículo 4).

15 Sorprende en cierto modo que no se utilizase el término "elección" en lugar del de "admisión” para nombrar este procedimiento como ya se hiciera en el Real Decreto 366 aprobado por el Partido Popular en 1997.

16 Este criterio de enfermedad crónica no estaba recogido en el proyecto de Ley que se aprobó en el Congreso, sin embargo fue añadido posteriormente en las enmiendas aprobadas por el Senado.

\section{Referencias}

Aguirre, E. (1997). Entrevista publicada en Cuadernos de Pedagogía, 255, 8-14.

Puelles Benítez, M. de. (2004b). Política y educación en la España contemporánea. Madrid: UNED.

Nogueira, R. (1988). Principios constitucionales del sistema educativo español. Madrid: MEC.

Ministerio de Educación y Ciencia (2004). Una educación de calidad para todos y entre todos. Propuestas para el debate. Madrid. Ministerio de Educación y Ciencia.

Fernández Rodríguez, J.M. (2000). Derechos de los padres. Contenido de la prestación educativa. Educadores, 193-194(42), 9-53.

Arasanz, Ll. (1999). El derecho a la educación y la libertad de enseñanza en las sentencias del Tribunal Constitucional español. 20 de septiembre de 1999. www.oidel.ch/publications/

Alegre Gómez, S. (1982). El Proyecto de Ley de financiación de la enseñanza obligatoria. Madrid: Dirección General de Estudios y Documentación.

Rodríguez Coarasa, C. (1998). La libertad de enseñanza en España. Madrid: Tecnos.

San Segundo, M.J. (2001). Economía de la educación. Madrid: Síntesis.

Vázquez Recio, R. (1999). El mito de la dirección: nuevos códigos para antiguas andanzas. Kikiriki, 53, 10-18.

Villamor Manero, P. (2007). La libertad de elección en educación, ¿̨objetivo o instrumento de las reformas educativas? Revista Complutense de Educación, v. 18, nº 2.

Villar Ezcurra, J.L. (1979). El derecho a la educación como servicio público. Revista de Administración Pública, 88, 155-207. 
200 Encounters/Encuentros/Rencontres 